\title{
How to Construct Curricula for Finance Professional under Credit System in China
}

\author{
Yuanyuan $\mathrm{Ma}^{1}$ \\ ${ }^{1}$ School of Finance \& Economics, Shandong Jiaotong University, Jinan, China \\ ${ }^{1}$ Correspondence: Yuanyuan Ma, 202, Unit 4, Building 4, Qilu Garden, Dikou Road, Tianqiao District, Jinan, \\ Shandong, China. Tel: 86-138-5314-6989. E-mail: myy_09@163.com
}

Received: July 15, 2014

doi:10.5430/ijhe.v3n3p114
Accepted: July 21, 2014

Online Published: July 28, 2014

URL: http://dx.doi.org/10.5430/ijhe.v3n3p114

This paper is sponsored the project "A research on the capability measure-based reform curriculum group --- taking Securities Investment for example" from Shandong Province Department of Education and the plan of great achievements spreading on teaching research based on the program "The teaching reform and innovation of finance professional" from Shandong Jiaotong University. The full text of this report may be reused under the condition of an acknowledgement and a correct reference to this publication.

\begin{abstract}
As a kind of teaching system, the credit system is constructed according to the elective system. It is benefit for improving teaching in implementing credit system. There are still some constraints during the transition from the academic year system to the credit one. In this paper, we shall first briefly introduce the bottleneck of credit system. The countermeasures are put forward to construct and perfect credit system, which adapted to the financial professional.
\end{abstract}

Keywords: Credit system, Teaching reform, Module construction, Teaching material system

Credit system is a set of rules of teaching management to measure students' learning effect by credit, which adopts the elective system instead of the academic year one. The teaching mode of academic year is relatively rigid. By comparison, credit system is flexibility to encourage students to develop their initiative fully. Credit system has been more and more commonly adopted in universities and colleges all over the world. The main traits are considered in flexible forms when operated. As long as the condition possesses, it is an inevitable tendency for higher education reform.

However, there are many constraints during the transition from the academic year system to the credit one for most universities and colleges in China. The challenges, for instance, increasing the difficulty of teaching, the lack of qualified teachers, dissolving the students' collective ideas and the undeveloped specialized course system, are inevitable for them. As far as the financial professional is concerned, the point is how to reform the credit system and restructure the course frame.

\section{Introduction}

In the mid-nineteenth century, credit system appeared in Europe and the United States. While the credit system in the modern sense originated from Harvard University. Charles Eliot, served as the president of Harvard University in the United States, officially announced implementation of a credit system. It was built on the elective system in 1872 after he had been to Germany and France. In view of educational philosophy, he advocated academic freedom, admitted differences the quality and ability of students, and respected the students' choices. And the idea fully met and developed everyone's interest and specialty, too.

Beijing University and other universities began to try out the credit system at the beginning of the 20th century. Until the 1990's, the implementation of the credit system in Chinese universities had come to four climaxes. Credit system gets a significant effect on embodying students' personality, developing students' potential, improving students' competence and enhancing the quality of personnel training.

The implementation of the credit system has its profound social background and the inner motivation. Firstly, it is 
necessary that the teaching content must be more flexible with the adjustment of industrial structures and the changes of economic growth mode. Secondly, learners require much more choices on the content and time to study with the differences in recruitment ways, students' sources and types of employment. Thirdly, the students are more urgent to pursuit character progress. In order to accommodate the changes, the idea that learners and managers hope to change the traditional teaching management mode arises spontaneously.

\section{The significance of implementation credit system}

\subsection{Course-selecting system strengthens students' learning autonomy}

Selection system is conducive to students' learning autonomy and pertinence. As far as the financial professional is concerned, it includes different specialized directions, such as insurance, commercial banks, securities investment and so on. Accordingly, many compulsory courses are set up to satisfy the qualified learning. We should not favor one more than the other in arrangement.

The curriculum design can strengthen financial theory basis and widen the realm of knowledge. But for the colleges who are oriented for training the specialized talents, it is unnecessary to pay great attention to wide knowledge and thick basis. For example, once the graduate is employed in the securities company, little of basic knowledge may be useful. However, the most specialized knowledge will be rendered useless, especially the previously knowledge of banking and insurance for those. On the one hand, the students take the time and effort in vain. On the other hand, the required knowledge, such as securities market, financial tools, portfolio and management, involves too little for them.

Through the implementation of the elective system, different specialty directions are set simultaneously to ensure that the students interested in different directions can focus on relevant professional courses. For example, the students who make up their mind to engage in securities investment focus mainly on financial marketing, investment and securities investment practice.

At the same time, the additional specialized curricula, such as the commercial bank management, international settlement, insurance science, can be as elective courses to be offered. Limited time and effort will be invested in a direction of study. As a result, the students have a much more positive initiative to learn the course, rather than will be forced to spend a great deal of energy to study the uninterested and unhelpful courses in the future. In addition, by the elective system, students can strengthen the weak aspects of professional knowledge.

\subsection{Tutorial system are helpful to improve the students' knowledge structure and comprehensive quality}

Once the tutorial system was put into effect, teachers would introduce professional situation and help students choose specialized courses according to their personal statement and interests. Furthermore, the detailed learning plan and reasonable structure of specialized knowledge can be guided by tutors to reduce the blindness of the learning. According to the students' professional directions, the tutors recommend them related materials, documents and books, as well lead students to engage in scientific research project. It follows from this that the students' comprehensive abilities to find problems, to analyze and solve problems can be improved, which is benefit for enhancing the career development potential.

\subsection{Flexible educational system is advantageous to arrange time reasonably and cut down expenditure}

The sources of students vary with the ways of recruit, which leads to the difference of student's knowledge base. As a result, their understanding levels are various even if they study the same courses. Of course, the time and energy required are different, too. If flexible educational system can be adopted, students can take a course in other courses in advance. Subsequent courses can be taken one after another as soon as the students lay a solid theoretical foundation, which can help them understand and master the content of the courses. For example, the students who are interested in investing course but poor in mathematics may adopt elastic length. What this means in practice is that the student can learn additional courses to help him understand and grasp the content of the courses. In response to changing conditions, the colleges and universities of western countries have adjusted accordingly many curricula of finance professional.

In addition, the credit system is advantageous to the reasonable arrangement of economic expenditure. With tuition rising year by year, there may be difficult for some families to pay for all four years of tuition. Flexible educational system can compress time to cut back the educational expenditures. In contrast, for the students who are economically able to support themselves but have difficulty in their studies while pursuing a full course of study, flexible educational system takes them more time to acquire credits. It means that increasing fiscal spending is a high price to pay for time to meet graduation requirements. 
Under the background, some universities and vocational colleges are tried out credit system in China, which opened the prologue of the credit system reform. Undoubtedly, this is really a good thing to promote the in-depth reform of education. Nonetheless, the history of the credit system in China is too short to implement smoothly. Not only there is a great difference on the ideology, but the education system is also hindering the overall implementation of the credit system. For the problems that exist in the implementation of credit system, we should deal with various contradictions seriously in view of the situations of Chinese education, which really plays the important role of the credit system in cultivating the excellent talents.

\section{The bottleneck of financial credit system}

The credit system has provided a broad platform for the financial course reform. However, in the process of the implementation of the credit system, adaptable teaching reform of finance professional relatively lags. Based on a thorough investigation on the present teaching situation of economic professional in Shandong, we found that the finance curriculum system doesn't adapt to credit system model, which mainly manifested in the following aspects.

\subsection{The educational idea lags}

All of the teachers need to adapt to the request of the credit system management mode from idea, not to mention action. The progressive education concepts, such as "student-oriented, principle of individualized instruction and personality development", have not been rooted deeply in the educators' mind. The popularization of higher education is inevitable, which due to the system of quality and evaluation does not correspond to each other. In addition, consciousness of relevant professional curriculum reform and innovation is not fully understood, and it is not suitable for the credit system model.

\subsection{The curricula are not scientific}

The flexibility and superiority of the credit system are difficult to realize if the curricula are set up improperly. As can be due to the lack of optional subjects which are suitable for professional direction and the personality training. Neither is the development dynamics of the course module inadequate. Nor the pertinence and adaptability of module are sufficient. As a result, the curricula and reform of the credit system are sometimes difficult to implement thoroughly.

A student, for instance, is interested in investing but deficient in mathematical thinking. It is a known fact that the quantity theory has become increasingly important in the finance discipline. He should have the basis of differential, integral calculus, linear algebra and mathematical statistics to understand and master the theory of "micro-finance" knowledge. Otherwise, there are difficulties in learning the course of investment, econometrics and financial engineering or something.

If all the students are offered the same courses mentioned above, some of the students may be no longer able to complete the study smoothly. Students may select some elementary courses in advance only if the flexible education system is adopted. The students will understand and master the content of the courses easily after laying a good foundation. More colleges and universities adapt to the changes in western countries and the teaching content in finance professional undergraduate are reinforced too.

\subsection{Textbook construction is still in a backward state}

Professional textbooks are developing beyond the old versions constantly in China. The problem lies in there is no breakthrough in the overall framework and system design. Textbooks available continue to follow the original model of the system, structure and patterns, which can't satisfy the implementation of the credit system. The contradictions are showed as follows.

Firstly, it does not meet the diversity of the talent demands of finance industry since the students' sources are various. Universities which focused on cultivating applied talents enroll not only the liberal art and science students, but the students coming from vocational high schools. In the meantime, run-through cultivation has become a general trend. Inevitably, diverse student sources need corresponding curriculum structure to be matched.

Secondly, the forms of teaching materials are single. A complete set of electronic, online, animated version has seldom been adopted but rather for the papery or static versions. The current material system goes against cultivating the students' autonomous learning ability because the multi-level textbooks system has not yet been built.

\subsection{Insufficient understanding on the value of specialized courses for the students}

This is mainly presented in the following. It takes subconsciously a long time for professional education to cultivate learners' rational thinking and improve their professional quality and ability. While due to the limitation of cognitive 
ability, most of the students can't be conscious enough of the fact that the financial professional courses play an important role in their sustainable development.

\section{Countermeasures to build and perfect the finance professional curriculum system suitable for credit system}

Construction of financial professional curriculum system is explored from the following two aspects. One is construction of the module of the course content system which matches very closely the credit system. The other is to build the construction of teaching material based on "students-oriented, principle of individualized instruction and self-learning". The innovating of teaching material system may fit the connotation of the credit system model.

\subsection{Building reasonable curriculum content module}

Based on the credit system, it is one of the effective ways to build the module system of finance professional courses. At the same time, the module system construction should follow the following principles.

\subsubsection{The principle of "necessary and sufficient"}

Following the first principle of "necessary", building module content resolves "what to teach". Secondly, the principle of "enough to use" satisfies the teaching requirements. In order to realize the goal of training "application-type" talents, it is unnecessary for most of the secondary colleges to pay much emphasis on over-broad knowledge and over-solid basis. According to statistics, less than $20 \%$ of the basic knowledge which precisely took many times are useful. In contrast, many professional curricula, such as the securities market $\&$ tools, portfolio and management are arranged too few to meet the demands. So we must promote a "small-type, short-time" courses.

4.1.2 The principle of "caring more about practice than theory"

In order to satisfy the demand of training applied talents with ability, module content should be built discriminatively. That is to say, acquisition of the experiences and strategies coming from practice is primary while understanding of the concept and principle is complementary

\subsubsection{The principle of "being scientific"}

When the course content is rebuilt and reordered, the framework should be logical and systematic considering of the logic of financial discipline itself. Financial curricula enjoy their own internal order. Supposing that the order is disrupted, finance knowledge as a whole will be artificially dismembered like some discrete points, which deviate from the relationship system of finance.

\subsubsection{The principle of "practicability"}

Curriculum module should be not only independent and scientific, but systematic and complete. Comprehensive knowledge module is benefit for the students' occupational development, professional quality and sustainable learning. At the same time, the needs of students' individuation can be met, too. There are a variety of target modes for student to select the courses. As a word, the capacity of course modules is expected to be systematic, reasonable and operable to manage and organize teaching orderly.

For example, the curriculum system will be perfected by "training and evaluation model of skilled ability". The model is mainly composed of the following five parts, the needs of qualified ability, curriculum system, teaching outline, ability-phase matrix and score chart of professional ability. In detail, the needs of specialized ability are the starting point of the model. Meanwhile, ability-phase matrix is formed combining students' cognitive stages. Each stage or each ability in the matrix is corresponding to specific project or tasks which is linked to curriculum evaluation point. And then the course outline and curriculum system are contacted together. Eventually score chart of specialized ability is a learning process for students, and it can quantitatively describe the student's current professional ability. The relationships among the parts are shown in Fig1.

\subsection{Improving the teaching material system}

In the process of construction, the teaching material system of financial professional should be geared to credit system. The "two combination" will be realized as following.

\subsubsection{Combination of autonomous development with extraneous introduction}

On the one hand, the basic module materials choose the authenticated planning materials. On the other hand, the module materials to improve the quality are mainly developed and written independently, let alone published. Through combining of independent development with extraneous introduction, the teaching material system basically meets the credit reform. Adaptable teaching reform in financial professional has the corresponding foundation platform under the credit system. 


\subsubsection{Combination paper medium with non-paper medium of teaching carriers}

Not only the paper- medium teaching carriers which adapt to the credit system model are necessarily formed, but also the non-paper-medium teaching carriers must be built based on the platform of financial professional network curricula with the increasing of the non-printing document resources. The forms are mainly digital and networked carriers, which include the design of teaching, learning method instruction, course quality standards, electronic teaching plan and electronic courseware, dynamic animation library, teaching video and financial culture materials, etc. Multi-level teaching carriers include learning system and examination system based on autonomous learning. It is an effective way for students to learn autonomously and asynchronously. In the meantime online communication and personal cultivation will be realized.

\section{Conclusion}

Credit system, with its flexible learning ways and unique personalized training scheme, is the inevitable trend for higher education to be adapted to the popular and international education. In addition, it combines the innovative educational concepts of "student-oriented, principle of individualized instruction". The most helpful approach to cultivate the talents satisfying the social demand is to reform in teaching. The credit system can improve the students' comprehensive quality and practical ability. At present, coordinated reform which matches with credit system model is immature, let alone adaptability of the course reform of financial professional. The exploratory work is far from enough and the additional research is needed.

\section{References}

Anderson L W, Krathwohl D R \& Airasian P W. (2001). A taxonomy for learning, teaching, and assessing: a revision of Bloom's taxonomy of educational objectives. New York: Longman.

Bin L. (2013). American university credit system and development background analysis. Heilongjiang province higher education research.

Cave. (1988). The Use of Performance Indicators in Higher Education: A Critical Analysis of Developing Practice. Jessica Kingsleg Publishers Ltd.

Gang C. (2012). The contradiction between credit system and current system of teaching management in colleges and universities. Heilongiiang province higher education.

Huaping L. (2011).Based on credit system in higher vocational higher mathematics curriculum system construction. Vocational education BBS.

Jing W, Zhonghua Y. (2014). The Research on Cultivating and Assessing Professional Ability under Credit System. Education Exploration.

John S Brubacher \& Willis Rudy. (1976). A History of American Colleges and Universities, 1636-1976, Harper \& Row Publishers.

Joseph T. Harder \& Jeffrey S. Harper. (2003). A Stage Model for Professional Development: Assessing Students and Curriculum in an MIS Program. Review of Business Information System.

Qingfeng C \& Yichun Z. (2008). Reform thinking and training object of financial professional in China based on globalization. Financial Teaching and Researching.

Ronghua M. (2009).Independent college financial personnel training mode study. Journal of financial and economic (academic). 